\title{
Proposal of a 'hot lock' as a barrier to fish invasion: an afterthought
}

\author{
Robert W. McCauley' \& Frederick E.J. Fry² \\ ' Department of Biology, Wilfrid Laurier University, Waterloo, Ontario N2L 3C5, Canada \\ ${ }^{2}$ Department of Zoology, University of Toronto, Toronto, Ontario M5S 1A4, Canada
}

Engineers may indeed prevail and a connection between the two river systems may be established (Balon et al. 1986, p. 267). Some means, however, must be found to prevent invading fish species passing from one river to the other. We propose a barrier to fish movement in the form of a nonpolluting lock of warmed water strategically placed in the canal system linking the two natural waterways. Perusal of upper lethal temperature data of fish (Coutant 1973) reveals that temperatures slightly below $40^{\circ} \mathrm{C}$ are acutely lethal at brief exposure to most species. This temperature, one or two degrees over normal body temperature, does not pose a danger to humans. In addition, fish will display avoidance reactions to the two attenuated warm boundaries of the heated reach of the canal.

The idea of a 'hot lock' is not new and was conceived, to our knowledge, for the first time by one of us (F.E.J.F.) in 1962 as a method of denying sea lampreys, Petromyzon marinus, access to the Trent Canal from Lake Huron. Lampreys would then have had the opportunity to expand their range to other inland lakes. It was planned to replace the marine railway, used to transport pleasure craft down the lower stretch of water falls separating Lake Huron from the Canal, by a lock. Laboratory experiments indicated that if this lock was heated to $39^{\circ} \mathrm{C}$, lampreys could not survive their passage in the warm water. Fortunately, it was not necessary to put this solution into practice since, on sober reflection, it was decided to retain the traditional and colourful method of transporting boats overland by the railway.

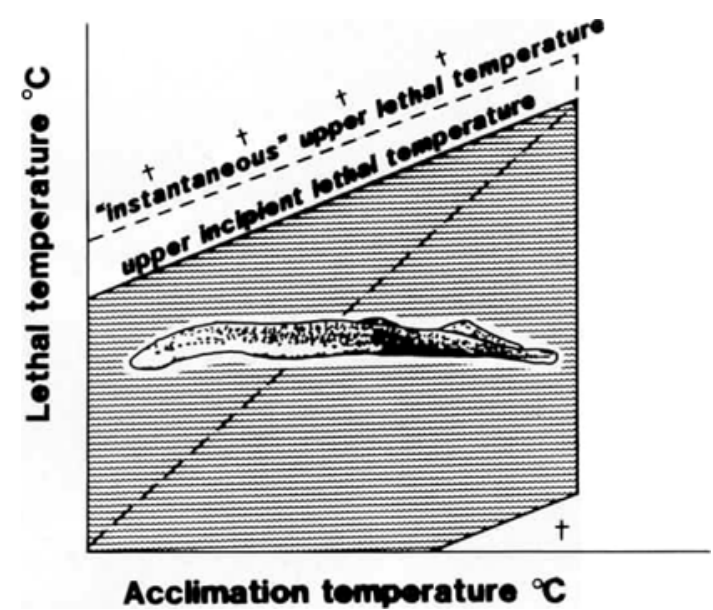

One objection to the creation of a 'hot lock' at the time was the high cost of maintaining elevated water temperatures in the lock. This objection is no longer applicable today since inexpensive calories may be supplied by a 'mini nuclear reactor' or by the waste warm effluent of a local power plant. Some technical problems are anticipated; for example, the confinement or dispersal of fog arising from the warm water and the conservation of heat. These could probably be solved by the ingenuity of the same engineers who designed the connecting waterway.

Balon, E.K., S.S. Crawford \& A. Lelek. 1986. Fish communities of the upper Danube River (Germany, Austria) prior to the new Rhein-Main-Donau connection. Env. Biol. Fish. 15: 243-27l (the preceding study).

Coutant. C.C. 1973. National Academy of Sciences water quality criteria. Environmental Protection Agency R 373033, Appendix II-C, Washington, D.C.

Received 6.11.1985 